\title{
Angiotensin II type 1 receptor-associated protein plays a role in regulating the local renin-angiotensin system in HSC-T6 cells
}

\author{
HAIYANG HUANG ${ }^{1}$, JIE ZHOU $^{1}$, ZHONGLIN CUI $^{1}$, BIAO WANG $^{1}$ and YUNWEI HU ${ }^{2}$ \\ ${ }^{1}$ Department of Hepatobiliary Surgery, Nanfang Hospital, Southern Medical University, Guangzhou, Guangdong 510515; \\ ${ }^{2}$ State Key Laboratory of Ophthalmology, Zhongshan Ophthalmic Center, Sun Yat-sen University, \\ Guangzhou, Guangdong 510060, P.R. China
}

Received January 15, 2014; Accepted November 10, 2014

DOI: $10.3892 / \mathrm{mmr} .2015 .3849$

\begin{abstract}
The aim of the current study was to examine the expression of the angiotensin II type 1 receptor-associated protein (ATRAP) in the rat hepatic stellate cell line HSC-T6 and to determine its interactions with the local renin-angiotensin system (RAS). To achieve this goal, the effect of stimulating HSC-T6 cells with angiotensin II (AngII) and angiotensin-(1-7) [Ang-(1-7)], on the expression of ATRAP, the angiotensin II type I receptor (AT1R), the Mas receptor and the angiotensin converting enzyme 2 (ACE2) 2, 6, 12, 18, 24 and $36 \mathrm{~h}$ after stimulation was investigated. Changes in expression were quantified at the gene and protein level using RT-qPCR and western blotting, respectively. A single dose of AngII $(1 \mu \mathrm{mol} / \mathrm{l})$ significantly increased the gene expression of ATRAP at $12 \mathrm{~h}$, whereas ACE2 gene expression levels were significantly increased at $6 \mathrm{~h}$ and then returned to baseline at $12 \mathrm{~h}$, prior to becoming significantly lower. A single dose of Ang-(1-7) at the same concentration as AngII induced ATRAP gene expression, which became statistically significant at the $6 \mathrm{~h}$ time-point, reached a peak at $12 \mathrm{~h}$ and remained elevated throughout the experimental time-course. In addition, ACE2 mRNA expression was significantly suppressed by Ang-(1-7) at $6 \mathrm{~h}$, reaching its lowest expression level at $24 \mathrm{~h}$. The expression of AT1R and the Mas receptor were unaffected by stimulation with AngII and Ang-(1-7). The western blotting results were generally consistent with the mRNA expression data. In conclusion, it was identified that ATRAP is endogenously expressed in HSC-T6 cells and therefore, may be critical in regulating the local RAS in these cells.
\end{abstract}

Correspondence to: Dr Jie Zhou, Department of Hepatobiliary Surgery, Nanfang Hospital, Southern Medical University, 1838 Guangzhou Road, Guangzhou, Guangdong 510515, P.R. China E-mail: zhoujie01@medmail.com.cn

Key words: angiotensin II type 1 receptor-associated protein, renin-angiotensin system, hepatic stellate cells

\section{Introduction}

It is well established that the renin-angiotensin system (RAS) contributes to a number of fibrogenic processes in the kidney $(1,2)$, heart $(2,3)$ and liver $(4,5)$. Angiotensin II (AngII) is formed from angiotensin I through the actions of the angiotensin converting enzyme (ACE); furthermore, AngII signaling through the angiotensin II type 1 receptor (AT1R) is an important mediator of the fibrogenic effects associated with the RAS. Accordingly, pharmacological blockers of AT1R or inhibitors of ACE are two ways to modulate this signaling pathway $(5,6)$. Previous evidence has also indicated that the formation of angiotensin-(1-7) [Ang-(1-7)] by ACE2 from either angiotensin I or AngII, may oppose AngII-mediated vascular and proliferative effects through the Mas receptor $(7,8)$. These pathways signify the existence of a regulatory balance in the RAS by two opposing arms: ACE-AngII-AT1R signaling and ACE2-Ang-(1-7)-Mas receptor signaling (9). Indeed, this is in agreement with the concept that all the components of the RAS have a specific role in maintaining the regulatory balance of the system $(9,10)$.

In addition to the components of the RAS mentioned, previous studies have focused attention on the AT1R-associated protein (ATRAP), a molecule that directly binds to the carboxyl-terminal domain of AT1R, however not with the AngII type 2 receptor (11-13). For example, it was observed that ATRAP is involved in the control of AT1R internalization, desensitization and phosphorylation and has a counter-regulatory effect on AT1R-mediated signal transduction pathway leading to pathological proliferation and fibrosis (11-13). The inhibitory function of AngII/AT1R signaling and its role in the tissue-specific regulatory balancing of the local RAS has been reported in studies of cardiovascular and renal cells, as well as for cardiac and vascular hypertrophy (14-16). Despite these associations with kidney and heart disease, no evidence has thus far been reported to determine the expression of ATRAP in hepatic stellate cells (HSCs), not to mention the potential role of ATRAP in local RAS regulation, or its association with the ACE-AngII-AT1R and ACE2-Ang-(1-7)-Mas receptor signaling axes in the liver.

In the present study, the hypothesis that HSCs are a target for ATRAP actions in regulating the balance of the RAS and in modulating the development of hepatic fibrosis was assessed. 
Table I. Primer sequences used for reverse transcription quantitative polymerase chain reaction.

\begin{tabular}{lll}
\hline Sequence name & & \multicolumn{1}{c}{ Primer sequence } \\
\hline AT1R & Forward & 5'-CCACTCAAGCCTGTCTACGA-3' \\
& Reverse & 5'-AGTGTGCTTTGAACCTGTCA-3' \\
Mas receptor & Forward & 5'-TGACCACCATGGAGTACGT-3' \\
& Reverse & 5'-TTCCGTATCTTCACCACCAA-3' \\
Angiotensin I-converting enzyme 2 & & \\
& Forward & 5'-ATGGACCGACAACGAAATG-3' \\
AT1R-associated protein & Reverse & 5'-CTCCCCAAAAGGAACTGTCT-3' \\
& & \\
$\beta$-actin & Forward & 5'-CTCTAGCCTCTGCGTTCTGA-3' \\
& Reverse & 5'-CACCAATGATGCTGTCACTCA-3' \\
& & Forward \\
\hline
\end{tabular}

AT1R, angiotensin II receptor type 1.

It was determined whether ATRAP was endogenously expressed in the rat HSC cell line, HSC-T6 and the effect of AngII and Ang-(1-7) on ATRAP expression was investigated.

\section{Materials and methods}

Cell culture. HSC-T6 cells were purchased from Shanghai Bogu Biotech Corporation (Shanghai, China) and cultured at $37^{\circ} \mathrm{C}$ in a $5 \% \mathrm{CO}_{2}$ atmosphere. The cells were cultured in high glucose Dulbecco's modified Eagle's medium (DMEM; Gibco Life Technologies, Grand Island, NY, USA) containing $10 \%$ fetal bovine serum (Hyclone, Logan, UT, USA), $100 \mathrm{U} / \mathrm{ml}$ penicillin and $100 \mu \mathrm{g} / \mathrm{ml}$ streptomycin (Hyclone). All experiments were performed using cells seeded in six-well plates. When the cells became adherent, they were incubated with DMEM serum-free medium for $24 \mathrm{~h}$ and then treated with control medium $\left(\mathrm{H}_{2} \mathrm{O}\right)$, or medium containing $1 \mu \mathrm{mol} / 1 \mathrm{AngII}$ (Sigma-Aldrich, St. Louis, MO, USA) or $1 \mu \mathrm{mol} / 1$ Ang-(1-7) (Sigma-Aldrich) for $2,6,12,18,24$ or $36 \mathrm{~h}$.

Gene expression analysis of ATIR, ATRAP, the Mas receptor and $A C E 2$. Reverse transcription quantitative polymerase chain reaction (RT-qPCR) was performed to detect the mRNA expression level of AT1R, ATRAP, the Mas receptor and ACE2 in HSC-T6 cells. Total RNA was extracted from the cells using TRIzol ${ }^{\circledR}$ reagent (Invitrogen Life Technologies, Carlsbad, CA, USA) according to the manufacturer's instructions and the cDNA was synthesized using the SuperScript First-Strand System (Promega, Beijing, China). PCR amplification was performed with SYBR Green qPCR Super mix (Invitrogen Life Technologies), using an ABI PRISM 7000 sequence detection system (Applied Biosystems, Foster City, CA, USA). The following cycling conditions were used: Initial denaturation at $50^{\circ} \mathrm{C}$ for $2 \mathrm{~min}$, followed by 40 cycles of denaturation at $95^{\circ} \mathrm{C}$ for $2 \mathrm{~min}$, primer annealing at $95^{\circ} \mathrm{C}$ for $15 \mathrm{sec}$ and primer extension at $60^{\circ} \mathrm{C}$ for $32 \mathrm{sec}$. The sequences of specific primer pairs are listed in Table I.
A comparative $\mathrm{Ct}(\mathrm{ddCt})$ method was used to compare the relative levels of mRNA expression and expression data were normalized to the reference gene $\beta$-actin (Invitrogen Life Technologies). All experiments were performed in triplicate.

Protein expression analysis of ATIR, ATRAP, the Mas receptor and $A C E 2$. Western blotting was used to confirm the RT-qPCR results at the protein level. Briefly, cells were centrifuged at $179 \mathrm{x}$ g for $10 \mathrm{~min}$ and washed twice with phosphate-buffered saline (Hyclone) and then lysed in protein extraction buffer (Cell Signaling Technology, Boston, MA, USA). The samples were then separated by SDS-PAGE and transferred to immobilon-P membranes (Millipore, Bedford, MA, USA). Following being blocked with 5\% fat-free milk for $1 \mathrm{~h}$ at room temperature or overnight at $4^{\circ} \mathrm{C}$, the membranes were incubated with the following primary antibodies: Anti-rat AT1R (1:500; Abcam, Cambridge, MA, USA; cat. no. ab-124505), ATRAP (1:200; Santa Cruz Biotechnology Inc., Santa Cruz, CA, USA; cat. no. sc-134652), Mas receptor (1:10,000; Abcam; cat. no. ab-156018) and ACE2 (1:1,000; Abcam; cat. no. ab-108252). All primary antibody incubations were performed for $2 \mathrm{~h}$ at $37.4^{\circ} \mathrm{C}$, followed by incubation with an appropriate secondary antibody. Finally, all the membranes were incubated with the Immobilon Western Chemiluminescent horseradish peroxidase Substrate (Millipore) and protein expression was analyzed quantitatively using the medical X-ray film XBT-1 (Kodak, Rochester, NY, USA). In all cases, the expression of glyceraldehyde-3-phosphate dehydrogenase (KangChen Bio-tech, Shanghai, China) was used as a reference protein.

Statistical analysis. SPSS 20.0 was used for statistical analyses (IBM, Armonk, NY, USA). All data are expressed as the mean \pm standard error of the mean. A one-way analysis of variance was used to analyze the expression of detected genes with the same treatment at different time-points, and a Student's t-test was used to determine the difference in 
A

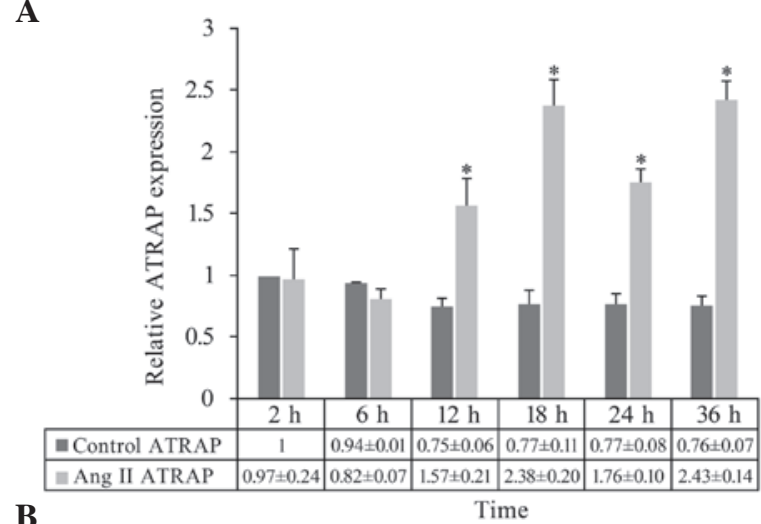

B

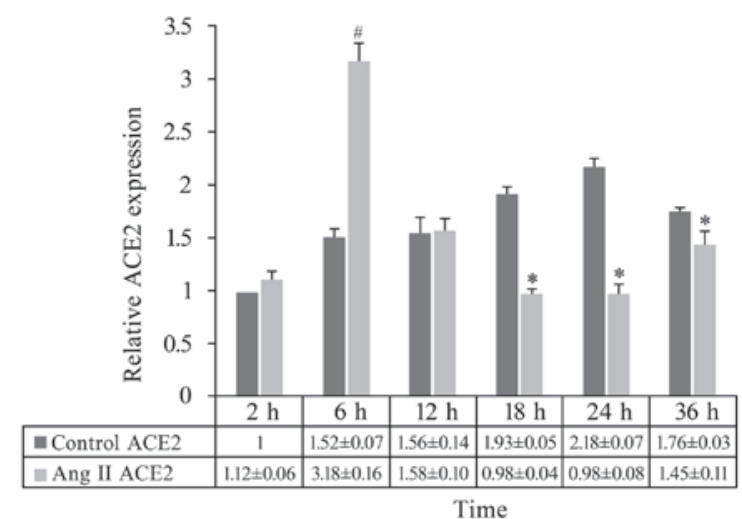

Figure 1. mRNA expression level of ATRAP and ACE2 in response to AngII treatment. Effect of AngII exposure on the mRNA expression level of (A) ATRAP and (B) ACE2 is shown. ${ }^{~} \mathrm{P}<0.05$ and ${ }^{*} \mathrm{P}<0.01$ compared with the control group at the corresponding time. ATRAP, angiotensin II type 1 receptor-associated protein; ACE2, angiotensin I-converting enzyme 2; AngII, angiotensin II.

expression level at the same observation time-point between the control and treatment groups. $\mathrm{P}<0.05$ was considered to indicate a statistically significant difference.

\section{Results}

Baseline gene expression in HSC-T6 cells. The mRNA expression level of AT1R, ATRAP, the Mas receptor and ACE2 was assessed in untreated HSC-T6 cells. No significant difference was identified in the expression of these genes at any time during the observation period $(\mathrm{P}>0.05)$, with the exception of ACE2 $(\mathrm{P}<0.001)$. ACE2 expression had a slight fluctuation, gradually increasing between 6 and $24 \mathrm{~h}$ and decreasing at $36 \mathrm{~h}$.

Altered gene expression in response to AngII stimulation. Following treatment with AngII, the gene and protein expression level of AT1R, ATRAP, the Mas receptor and ACE2 was assessed (Figs. 1 and 2). No difference in the expression level of AT1R or the Mas receptor was identified at the gene or protein level. By contrast, the mRNA expression level of ATRAP $(\mathrm{P}<0.001)$ and ACE2 $(\mathrm{P}<0.001)$ was significantly altered by AngII stimulation. Specifically, ATRAP was highly induced $12 \mathrm{~h}$ after stimulation $(\mathrm{P}<0.005)$ and remained elevated at the 18, 24 and $36 \mathrm{~h}$ time-point (all $\mathrm{P}<0.001$; Fig. $1 \mathrm{~A}$ ). ACE2 expression was significantly induced at $6 \mathrm{~h}(\mathrm{P}<0.05)$, returned to baseline at $12 \mathrm{~h}$ and was significantly repressed at 18,24 and
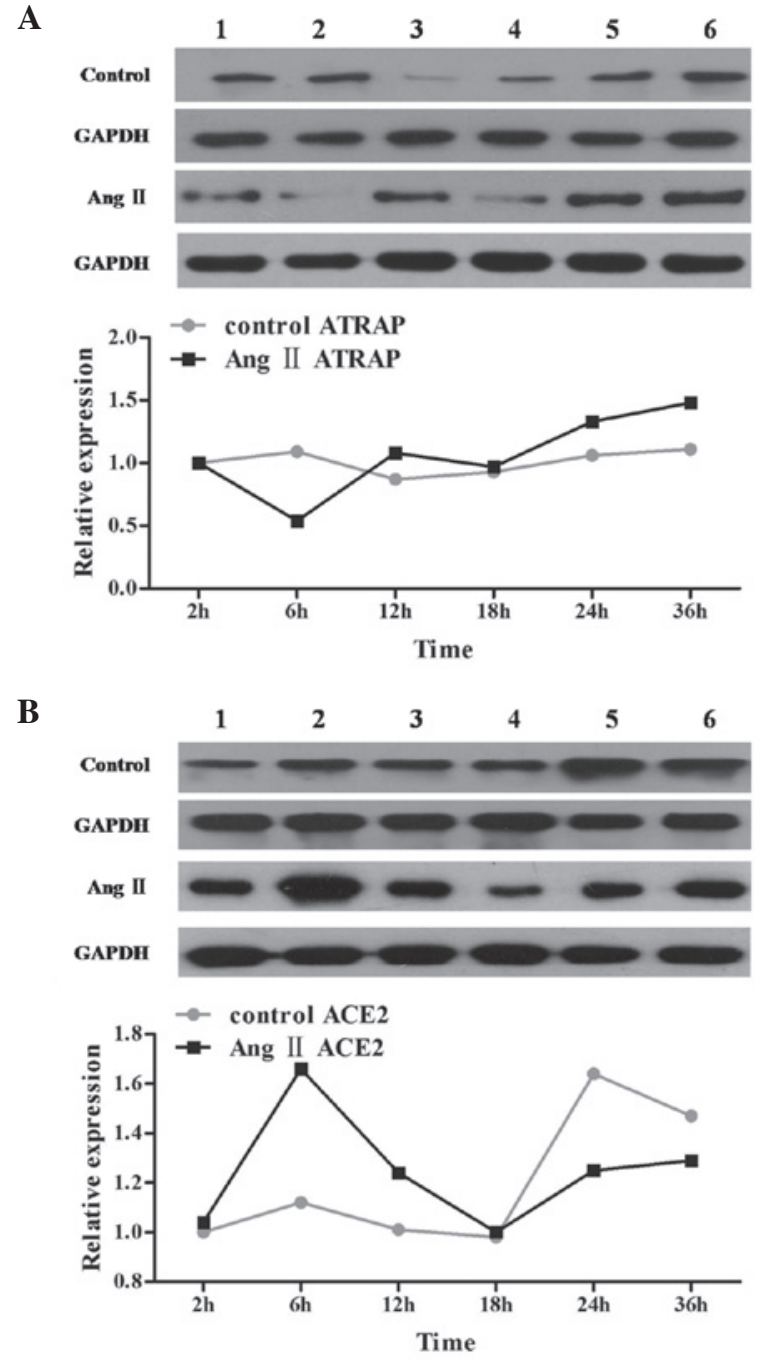

Figure 2. Protein expression level of ATRAP and ACE2 in response to AngII treatment. Representative western blot analysis data are shown for the expression levels of (A) ATRAP and (B) ACE2 in response to AngII stimulation (upper panels). The quantification of protein expression levels is also shown relative to the control group at $2 \mathrm{~h}$ (lower panels). From left to right, lanes 1-6 were samples from the treatment and control groups collected 2, 6, 12, 18, 24 and $36 \mathrm{~h}$ after treatment. ATRAP, angiotensin II type 1 receptor-associated protein; ACE2, angiotensin I-converting enzyme 2; AngII, angiotensin II.

$36 \mathrm{~h}$ (all $\mathrm{P}<0.001$; Fig. 1B). The change in the protein expression level of ATRAP (Fig. 2A) and ACE2 (Fig. 2B) in response to AngII stimulation was in agreement with the changes in their mRNA level.

Altered gene expression in response to Ang-(1-7) stimulation. Following treatment with Ang-(1-7), the gene and protein expression level of AT1R, ATRAP, the Mas receptor and ACE2 was assessed (Figs. 3 and 4). Similarly to AngII, Ang-(1-7) treatment had no effect on the expression level of AT1R or the Mas receptor. By contrast, ATRAP mRNA expression was significantly upregulated at the $6,12,18,24$ and $36 \mathrm{~h}$ time-points (all $\mathrm{P}<0.05)$, reaching a peak of induction $12 \mathrm{~h}$ after treatment (Fig. 3A). A similar change in the protein expression level of ATRAP was also observed in response to Ang-(1-7) treatment (Fig. 4A). By contrast, ACE2 mRNA expression was suppressed by Ang-(1-7), reaching a significantly lower 
A

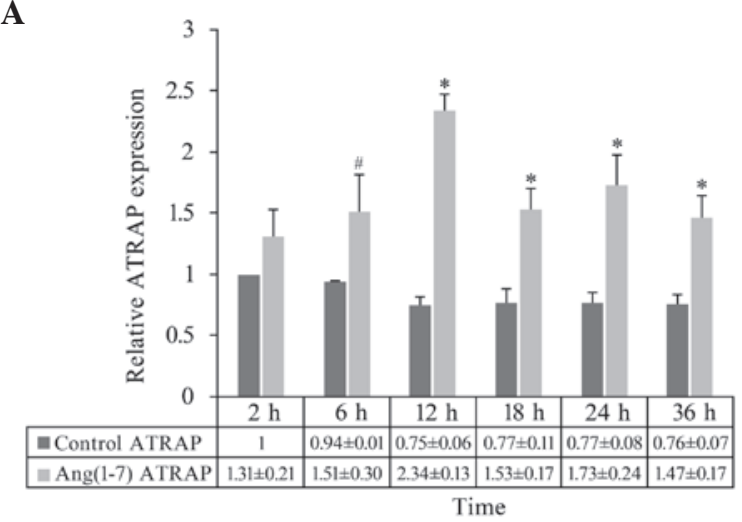

B

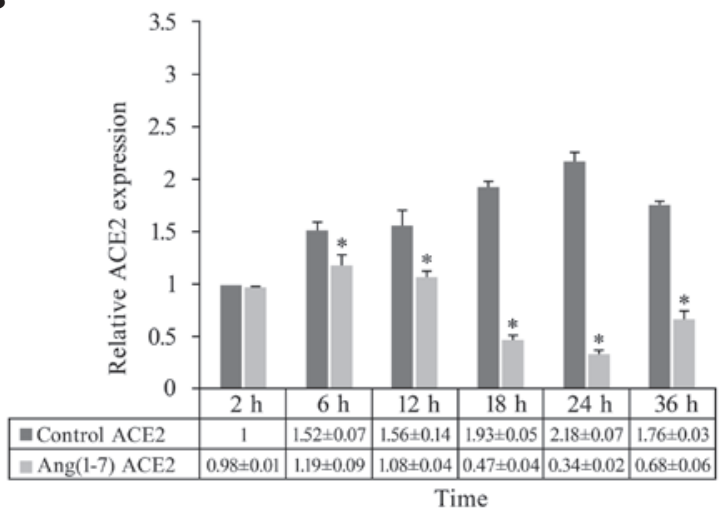

Figure 3. mRNA expression levels of ATRAP and ACE2 in response to Ang-(1-7) treatment. Effect of Ang-(1-7) exposure on the mRNA expression level of (A) ATRAP and (B) ACE2 is shown. ${ }^{*} \mathrm{P}<0.05$ and ${ }^{*} \mathrm{P}<0.01$ compared with the control group at the corresponding time. ATRAP, angiotensin II type 1 receptor-associated protein; ACE2, angiotensin I-converting enzyme 2; Ang, angiotensin.

level at the $6 \mathrm{~h}$ time-point $(\mathrm{P}<0.01)$ and continuing to decrease until reaching a nadir at $24 \mathrm{~h}(\mathrm{P}<0.001$; Fig. 3B). As with the previous results, the changes in the mRNA expression level of ACE2 were confirmed at the protein level (Fig. 4B).

\section{Discussion}

ATRAP is endogenously expressed in HSC-T6 cells. The HSC-T6 cell line is regarded as a reliable model for the study of liver fibrosis in vitro. It exhibits an activated phenotype reflected by a fibroblast-like shape and rapid proliferation (17). It is known that quiescent HSCs barely express any components of the RAS, while activated HSCs highly express active renin and ACE and secrete AngII (18). In the present study, it was reported that AT1R, ATRAP, the Mas receptor and ACE2 are expressed in HSC-T6 cells without stimulation by any angiotensin peptide and all these genes, with the exception of ACE2 are maintained at a constant level while being cultured in vitro. Treatment with AngII and Ang-(1-7) triggered responses in the HSC-T6 RAS, resulting in altered expression of ATRAP and ACE2. The present data suggests that although the HSC-T6 cell line was isolated from quiescent rat HSCs, it exhibits the characteristics of activated rat HSCs, expressing the components of the RAS and reacting to changes in this system.

It has previously been reported that ATRAP mRNA is abundant in the kidney, heart and testis, but is poorly expressed in the liver (19). The expression of ATRAP in
A
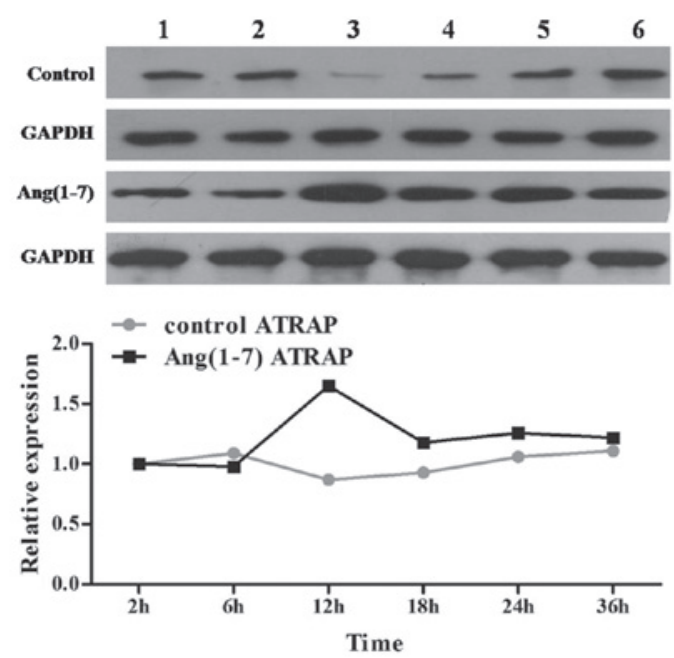

B

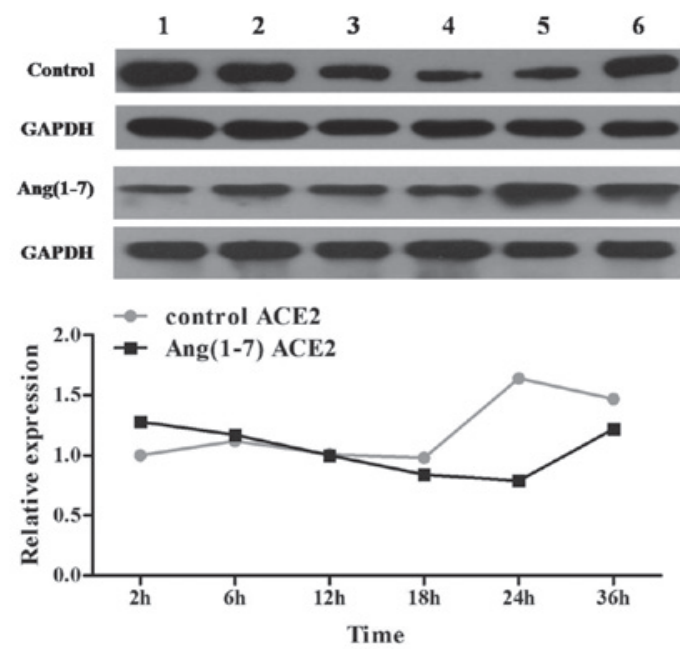

Figure 4. Protein expression levels of ATRAP and ACE2 in response to Ang-(1-7) treatment. Representative western blot analysis data is shown for the expression levels of (A) ATRAP and (B) ACE2 in response to Ang-(1-7) stimulation (upper panels). Quantification of protein expression levels is also shown relative to the control group at $2 \mathrm{~h}$ (lower panels). From left to right, lanes 1-6 were samples from the treatment and control groups collected at 2, 6, 12, 18, 24 and $36 \mathrm{~h}$ after treatment. ATRAP, angiotensin II type 1 receptor-associated protein; ACE2, angiotensin I-converting enzyme 2; Ang, angiotensin.

HSC-T6 cells has not been reported previously, thus to the best of our knowledge, the present study is the first to identify that ATRAP is endogenously expressed at the mRNA and protein levels in HSC-T6 cells and responds to stimulation by AngII and Ang-(1-7).

Previous studies $(14-16,20-23)$ have demonstrated that ATRAP is a novel molecule able to downregulate AT1R signaling to suppress AngII induced hypertrophic and proliferative responses in cardiovascular or renal tissue and cells and has a regulatory role in balancing the local RAS. The effect of AngII on ATRAP expression in HSCs has not previously been described; however, it is reported in the present study, for the first time to the best of our knowledge, that AngII stimulates the expression of ATRAP in HSC-T6 cells. Notable, Wakui et al (16) identified that ATRAP expression decreased in the kidney of mice following chronic AngII-infusion, 
while its expression level in the liver was not affected. The difference in results between the study by Wakui et al (16) and the current study may be explained by differences in the model used, making comparisons between the two results difficult. Specifically, Wakui et al (16) investigated the effects of continuous AngII-infusion in vivo, whereas in the present study the effects of a one-time AngII treatment on HSC-T6s cells were investigated in vitro. By contrast, the present results are similar to previous studies demonstrating that AngII stimulates ATRAP expression in vascular smooth muscle cells, with no effect on AT1R expression (24). In addition, AngII stimulation was reported to provoke internalization of AT1R in an investigation using cardiomyocytes (25). It was hypothesized that the AT1R internalization, which was a known effect of ATRAP on AT1R $(11-13,19)$, may reflect the increased ATRAP expression to a certain extent. Therefore, this finding suggested that AngII induced ATRAP expression, which in turn induced AT1R internalization.

As discussed previously, equilibrium is maintained in the RAS, at least in part by signaling through the ACE-AngII-AT1R and ACE2-Ang-(1-7)-Mas receptor axes. Previously published studies in liver disease $(4,26)$ demonstrating the ACE2-Ang-(1-7)-Mas receptor axis represent a counter-regulatory arm of locally produced AngII. In the present study, it was hypothesized that low dose AngII may stimulate HSC-T6 cells, giving rise to AT1R signaling and inducing their proliferation, as well as inducing the expression of counter-regulatory factors. The present results revealing significantly increased expression of ACE2 at early stages suggest that the ACE2-Ang-(1-7)-Mas receptor axis was induced and the mechanism of balance was initiated by AngII. Based on the balance mechanism, it is possible that the induction of ATRAP countered signaling through the ACE-AngII-AT1R axis. Whilst in the study of Wakui et al (16), mentioned previously, activation of AT1R signaling had a dominant effect over counter-regulatory factors such as ATRAP under chronic AngII infusion, resulting in suppression of ATRAP.

Notably, although AngII induced the expression of ATRAP in HSC-T6 cells, AT1R expression was unaltered. This finding is consistent with the existing literature $(16,24)$ and suggests that increased ATRAP expression affected the internalization, desensitization or phosphorylation of AT1R, however, had no effect on its expression.

There have been multiple investigations into the effect of Ang-(1-7) treatment on the expression of RAS components in tissues or cell lines, however, the majority of these studies were conducted with drugs used to increase Ang-(1-7) levels indirectly, including ACE inhibitors and AT1R blockers $(27,28)$. However, these drugs may also interfere with the RAS in other ways, thus the direct actions of Ang-(1-7) may have been obscured. Tan et al (29) avoided this shortcoming and reported on the direct regulatory effects of Ang-(1-7) on the expression of ACE2 and Mas receptors in the rat kidney and heart. To the best of our knowledge, the direct regulatory effect of Ang-(1-7) on ATRAP expression in liver tissue or hepatic cells has not been reported previously. In the present study, it was reported that Ang-(1-7) is able to induce ATRAP expression in HSC-T6 cells, having an effect similar to that of AngII. It is theorized that this upregulation reflects a compensatory mechanism of the ACE-AngII-AT1R signaling pathway, to counteract against the increased signaling through the ACE2-Ang-(1-7)-Mas receptor pathway. Furthermore, this result indicates that the expression of ATRAP is more sensitive to AngII than Ang-(1-7).

In conclusion, the present study establishes the existence of a local regulatory network for the RAS in HSC-T6 cells and is the first, to the best of our knowledge, to confirm that these cells endogenously express ATRAP. The present data indicate that ATRAP acts to maintain balance in the local RAS through its antagonistic effect on AngII expression, as evidenced by the observation that ATRAP is upregulated by AngII and Ang-(1-7) exposure.

\section{References}

1. Yu L, Nobel NA and Border WA: Therapeutic strategies to halt renal fibrosis. Curr Opin Pharmacol 2: 177-181, 2002.

2. Kim S and Iwao H: Molecular and cellular mechanisms of angiotensin II-mediated cardiovascular and renal diseases. Pharmacol Rev 52: 11-34, 2000

3. Unger T: The role of the renin angiotensin system in the development of cardiovascular disease. Am J Cardiol 89: 3A-9A, 2002.

4. Warner FJ, Lubel JS, McCaughan GW and Angus PW: Liver fibrosis: a balance of ACEs? Clin Sci (Lond) 113: 109-118, 2007.

5. Paizis G, Gilbert RE, Cooper ME, Murthi P, Schembri JM, Wu LL, Rumble JR, Kelly DJ, Tikellis C, Cox A, Smallwood RA and Angus PW: Effect of angiotensin II type 1 receptor blockade on experimental hepatic fibrogenesis. J Hepatol 35: 376-385, 2001.

6. Munshi MK, Uddin MN and Glaser SS: The role of the renin-angiotensin system in liver fibrosis. Exp Biol Med (Maywood) 236: 557-566, 2011.

7. Simões e Silva AC, Pinheiro SV, Pereira RM, Ferreira AJ and Santos RA: The therapeutic potential of Angiotensin-(1-7) as a novel Renin-Angiotensin System mediator. Mini Rev Med Chem 6: 603-609, 2006

8. Carey RM and Siragy HM: Newly recognized components of the renin-angiotensin system: potential roles in cardiovascular and renal regulation. Endocr Rev 24: 261-271, 2003.

9. Iwai $\mathrm{M}$ and Horiuchi M: Devil and angel in the renin-angiotensin system: ACE-angiotensin II-AT1 receptor axis vs. ACE2-angiotensin-(1-7)-Mas receptor axis. Hypertens Res 32: 533-536, 2009.

10. Pereira RM, dos Santos RA, da Costa Dias FL, Teixeira MM and Simões e Silva AC: Renin-angiotensin system in the pathogenesis of liver fibrosis. World J Gastroenterol 15: 2579-2586, 2009.

11. Guo DF, Sun YL, Hamet P and Inagami T: The angiotensin II type 1 receptor and receptor-associated proteins. Cell Res 11: 165-180, 2001.

12. Wang W, Huang Y, Zhou Z, Tang R, Zhao W, Zeng L, Xu M, Cheng $\mathrm{C}$, Gu S, Ying K, Xie Y and Mao Y: Identification and characterization of AGTRAP, a human homolog of murine angiotensin II receptor-associated protein (Agtrap). Int J Biochem Cell Biol 34: 93-102, 2002.

13. Lopez-Ilasaca M, Liu X, Tamura K and Dzau VJ: The angiotensin II type I receptor-associated protein, ATRAP, is a transmembrane protein and a modulator of angiotensin II signaling. Mol Biol Cell 14: 5038-5050, 2003.

14. Tamura K, Wakui H, Maeda A, Dejima T, Ohsawa M, Azushima K, Kanaoka T, Haku S, Uneda K, Masuda S, Azuma K, Shigenaga A, Koide Y, Tsurumi-Ikeya Y, Matsuda M, Toya Y, Tokita Y, Yamashita A and Umemura S: The physiology and pathophysiology of a novel angiotensin receptor-binding protein ATRAP/Agtrap. Curr Pharm Des 19: 3043-3048, 2013.

15. Wakui H, Tamura K, Masuda S, et al: Enhanced angiotensin receptor-associated protein in renal tubule suppresses angiotensin-dependent hypertension. Hypertension 61: 1203-1210, 2013.

16. Wakui H, Tamura K, Matsuda M, Bai Y, Dejima T, Shigenaga A, Masuda S, Azuma K, Maeda A, Hirose T, Ishigami T, Toya Y, Yabana M, Minamisawa S and Umemura S: Intrarenal suppression of angiotensin II type 1 receptor binding molecule in angiotensin II-infused mice. Am J Physiol Renal Physiol 299: F991-F1003, 2010. 
17. Vogel S, Piantedosi R, Frank J, Lalazar A, Rockey DC, Friedman SL and Blaner WS: An immortalized rat liver stellate cell line (HSC-T6): a new cell model for the study of retinoid metabolism in vitro. J Lipid Res 41: 882-893, 2000.

18. Bataller R, Sancho-Bru P, Ginès P, Lora JM, Al-Garawi A, Solé M, Colmenero J, Nicolás JM, Jiménez W, Weich N, Gutiérrez-Ramos JC, Arroyo V and Rodés J: Activated human hepatic stellate cells express the renin-angiotensin system and synthesize angiotensin II. Gastroenterology 125: 117-125, 2003.

19. Daviet L, Lehtonen JY, Tamura K, Griese DP, Horiuchi M and Dzau VJ: Cloning and characterization of ATRAP, a novel protein that interacts with the angiotensin II type 1 receptor. J Biol Chem 274: 17058-17062, 1999.

20. Cui T, Nakagami H, Iwai M, Takeda Y, Shiuchi T, Tamura K, Daviet L and Horiuchi M. ATRAP, novel AT1 receptor associated protein, enhances internalization of AT1 receptor and inhibits vascular smooth muscle cell growth. Biochem Biophys Res Commun 279: 938-941, 2000

21. Wakui H, Tamura K, Tanaka Y, Matsuda M, Bai Y, Dejima T, Masuda S, Shigenaga A, Maeda A, Mogi M, Ichihara N, Kobayashi Y, Hirawa N, Ishigami T, Toya Y, Yabana M, Horiuchi M, Minamisawa S and Umemura S: Cardiac-specific activation of angiotensin II type 1 receptor-associated protein completely suppresses cardiac hypertrophy in chronic angiotensin II-infused mice. Hypertension 55: 1157-1164, 2010.

22. Wakui H, Dejima T, Tamura K, Uneda K, Azuma K, Maeda A, Ohsawa M, Kanaoka T, Azushima K, Kobayashi R, Matsuda M, Yamashita A and Umemura S: Activation of angiotensin II type 1 receptor-associated protein exerts an inhibitory effect on vascular hypertrophy and oxidative stress in angiotensin II-mediated hypertension. Cardiovasc Res 100: 511-519, 2013.
23. Oppermann M, Gess B, Schweda F and Castrop H: Atrap deficiency increases arterial blood pressure and plasma volume. J Am Soc Nephrol 21: 468-477, 2010.

24. Li Z, Wang ZG, Chen X and Chen XD. Inhibitory effect of angiotensin II type 1 receptor-associated protein on vascular smooth muscle cell growth and neointimal formation. Chin Med Sci J 22: 22-26, 2007.

25. Tanaka Y, Tamura K, Koide Y, et al: The novel angiotensin II type 1 receptor (AT1R)-associated protein ATRAP downregulates AT1R and ameliorates cardiomyocyte hypertrophy. FEBS Lett 579: 1579-1586, 2005.

26. Lubel JS, Herath CB, Tchongue J, Grace J, Jia Z, Spencer K, Casley D, Crowley P, Sievert W, Burrell LM and Angus PW:Angiotensin-(1-7), an alternative metabolite of the renin-angiotensin system, is up-regulated in human liver disease and has antifibrotic activity in the bile-duct-ligated rat. Clin Sci (Lond) 117: 375-386, 2009.

27. Ferrario CM, Jessup J, Chappell MC, Averill DB, Brosnihan KB, Tallant EA, Diz DI and Gallagher PE: Effect of angiotensin-converting enzyme inhibition and angiotensin II receptor blockers on cardiac angiotensin-converting enzyme 2. Circulation 111: 2605-2610, 2005.

28. Igase M, Strawn WB, Gallagher PE, Geary RL and Ferrario CM: Angiotensin II AT1 receptors regulate ACE2 and angiotensin-(1-7) expression in the aorta of spontaneously hypertensive rats. Am J Physiol Heart Circ Physiol 289: H1013-H1019, 2005.

29. Tan Z, Wu J and Ma H: Regulation of angiotensin-converting enzyme 2 and Mas receptor by Ang-(1-7) in heart and kidney of spontaneously hypertensive rats. J Renin Angiotensin Aldosterone Syst 12: 413-419, 2011. 